\title{
La ciudadanía y los derechos humanos
}

Autor: Hernández González, Mónica del Mar (Maestro. Especialidad en Educación Infantil).

Público: Maestros. Materia: Educación para la ciudadanía. Idioma: Español.

Título: La ciudadanía y los derechos humanos.

\section{Resumen}

La educación para la ciudadanía y los derechos humanos son aspectos de vital importancia en el día a día de niños y adultos. A lo largo de este artículo se destaca la importancia de que los niños y niñas conozcan la importancia de los mismos desde las primeras edades para que sean ciudadanos activos y responsables. Las aulas de educación primaria, se convierten así en un espacio único para desarrollar estos conocimientos y actitudes. Se enuncia una batería de actividades que promueven dichos conocimientos a través de un enfoque competencial y funcional.

Palabras clave: ciudadanía, derechos humanos, alumnado, maestros.

Title: Citizenship and human rights.

\section{Abstract}

Education for citizenship and human rights are vitally important aspects in the day-to-day life of children and adults. Throughout this article, it is important for children to be aware of their importance from the earliest ages so that they are active and responsible citizens. The classrooms of primary education, thus become a unique space to develop this knowledge and attitudes. A battery of activities that promote this knowledge through a competential and functional approach is enunciated.

Keywords: Human rights, citizenship, students, teachers.

Recibido 2017-01-29; Aceptado 2017-02-13; Publicado 2017-02-25; Código PD: 080125

La educación para la ciudadanía es un aspecto en el que se insiste desde la Unión Europea para fomentar la ciudadanía responsable en una sociedad democrática como fórmula para lograr la cohesión social y una entidad europea común.

Es importante trabajar con el alumando actitudes que les permitan de manera progresiva:

- Participar de manera activa en la sociedad

- Trabajar en equipo y fomentar la cooperación

- Tener conocimiento de los derechos humanos

- Iniciarse en la democracia a través de actividades que les permitan comprender la importancia de este sistema político

- Adquirir actitudes responsables, participativas y solidarias

Se pretende que niños y niñas se incorporen a la vida adulta de manera satisfactoria y sean capaz de desarrollar un aprendizaje permanente a lo largo de la vida. Para ello es importante que se integren todos los aprendizajes, y permitir a todos los estudiantes integrar sus aprendizajes en diferentes situaciones y contextos.

Para conseguirlo, es importante conocer qué saben nuestros alumnos/as para poder poner el punto de incio en nuestra labor educativa como maestros/as. Del mismo modo, es vital plantear situaciones y actividades en las que se parta de lo conocido, de lo cercano y familiar para ir de manera pogresiva ampliando conocimientos. Esto creará aprendizajes significativos, funcionales y competenciales, algo que tiene como fin que el alumando extrapole más allá del ámbito educativo las actitudes y aptitudes adquiridas a lo largo del proceso de enseñanza y aprendizaje.

La educación para la ciudadanía y los derechos humanos se relaciona directamente con áreas del currículo de Educación Primaria

- Conocimiento del medio natural, social y cultural: la impulsación de la autonomía personal, autoestima, la asunción de hábitos sociales, la manifestación del criterio propio, el respeto a las opiniones ajenas y el respeto a los otros, el diálogo, la negociación en caso de conflicto en el ámbito familiar y escolar.

- Lengua Castellana y Literatura: permite comunicar y transmitir conocimientos, dudas e inquietudes 
- Música: presente en cualquier lugar en el que $n$ os encontramos y sobre todo en los diversos hábitats existentes

- Lengua Extranjera: nos ayuda a ver otras realidades diferentes y enriquecedoras

Dada la importancia del trabajo desde las primeras edades en las aulas, muestro a continuación una batería de actividades motivadoras y activas que pretenden acercar al alumnado al tema abordado.

Como en cada práctica educativa será necesario conocer las carcterísticas piscoevolutivas del alumnado con el que trabajamos para modificar y adaptar las actividades a las características del grupo en general y las características individuales de cada niño/a.

1. Aventura fascinante. Animado e interactivo diseñado por la Oficina del Alto Comisionado de las Naciones Unidas para los Derechos Humanos y adecuado para alumnos de Primaria, que pueden profundizar en los derechos humanos, el respeto y la tolerancia a través de seis minijuegos.

2. Materiales para la educación en derechos humanos. Propuesta de Amnistía Internacional y la Red de Escuelas por los Derechos Humanos.

3. ABC: La enseñanza de los derechos humanos. Capítulo tercero de esta publicación de la Oficina del Alto Comisionado de las Naciones Unidas para los Derechos Humanos en el que se recopilan actividades prácticas recomendadas para tercer ciclo de Primaria y primer ciclo de Secundaria.

4. Contra viento y marea. Este completo juego desarrollado por ACNUR trata el tema de los refugiados desde un punto de vista muy cercano, involucrando a los alumnos en primera persona. Puede servir para repasar con ellos puntos como el derecho a no ser sometido a torturas, penas o tratos crueles, el derecho a circular libremente, o a buscar asilo en cualquier país.

5. El cine, el mundo y los derechos humanos. Portal para comprender el mundo a través del cine y desde el compromiso con los Derechos Humanos; cuenta con materiales didácticos para trabajar diversas películas. 